\title{
The Design Culture: Actions and Narratives Between Archives and Exhibitions
}

\author{
Raffaella Trocchianesi ${ }^{1}$ \\ Politecnico di Milano \\ raffaella.trocchianesi@polimi.it \\ ORCID 0000-0003-1724-0345
}

\author{
Francesca Zanella ${ }^{1}$ \\ Università degli Studi \\ di Modena e Reggio Emilia \\ francesca.zanella@unimore.it \\ ORCID 0000-0003-4373-0460
}

\begin{abstract}
The article is focused on the value of design archives as resources to be enhanced through exhibitions, and as heritage for innovation based on process of knowledge re-use, especially for creative industries.

Starting from the background of the debate on the new dimension of the archive (especially the one focused on the relation between art and design practices and the archive), the article will focus on a specific context as the one of design archives which have been in recent years particularly vivid realities. Focusing on designer's archive (in between the broader system of design documentation), and through a case study such as CSAC of Università degli Studi di Parma, we will examine how these archives are not merely repositories of drawings and how they can be connectors for creative industries, through exhibitions and other programs.

In the second part of the article, we will focus on three exhibitions devoted to design which are expressions of a huge patrimony organized in structured archives, analysing different curatorial practices and narratives paradigms. In these cases, design exhibitions are 'active' representation of design archives.
\end{abstract}

\section{Keywords}

Archives

Exhibitions

Design culture 


\section{Design Archives: \\ Enhancement and Relational Devices}

In 2001 the Italian firm Danese produced Archivio vivo, a metal book stand designed by James Irvine, an object to be hung on the wall or placed on a table.

This light and discrete new object was conceived exactly in the same years when the archive was undergoing a profound transformation both in the domain of creation, management and preservation practices and methodologies and in the wide perception by different community users. This object too, created by a designer, should have contributed to several changings in the way of archiving, as it is designed for an easily display of books, objects or drawings and texts, dismantling the accuracy of archival classification and storage.

For a long time archiving and exhibiting have pertained to antithetic domains.

The archive has been for centuries an organization devoted to the collecting of documents, their preservation "because of their enduring value", just to preserve their original physical structure and to guarantee their authenticity.

The museum collects and preserves artworks defining their value through their exhibition.

During the second half of 20th century such a sharp distinction started to blur. After Foucault (1969) and Derrida (1995) the archive has not been intended only as the result of a natural process but as a social one, determined by politics and economy.

In the information society archives and documents are becoming even more crucial; access for an increasingly wider audience is a priority, and archivists are aware that archives are selective memories.

The digital turn and a new role of archivists as performers, mainly devoted to the analysis of the process than to the archival systems, contributed to the acquiring of the consciousness of the archive as an "organizing and enabling 'device'" (Lupo, 2013, p. 142), and as a process (Noordegraaf, 2011).

The archive is intended as a place of the knowledge, decolonization and re-semantization (Foster, 2004; Baldacci, 2016), even a resource for the museum's new narratives, the tools for the activation of new relations between the museum, its context and its public through a multiplicity of actions: from the exhibition, to the contamination between artworks, objects and digital environments.

We should mention the L'Internationale, project funded by the European Commission and led by seven European museums ${ }^{2}$, which intended the archive as a place of "emergence of radical intervention strategies in the construction processes of new post-national archival imaginaries but also the emergence of new instituting practices, conscious of art museums' politics, geopolitics, and the biopolitics of the archive." (Decolonising, 2016)

However, the archive, as it was assumed in several projects undergoing L'Internationale, continues to be almost the 'guardian of the memory', an essential and sometimes collateral source for narratives, due to a probably unsolved distinction between artwork and document (Zanella, 2019).
Ra aella Trocchianesi is author of Exhibitions as a Narrative Display of Archives and Conclusions. Francesca Zanella is author of Design Archives: Enhancement and Relational Devices.

$$
2
$$

Moderna galerija, Ljubljana, Museo Nacional Centro de Arte Reina Sofía, Madrid, Museu d'Art Contemporani Barcelona, Museum van Hedendaagse Kunst Antwerpen, Muzeum Sztuki Nowoczesnej w Warszawie, SALT Istanbul and Ankara, Van Abbemuseum Eindhoven. 
In analogy we should consider design archives which are not necessarily qualified and conditioned by the assignment or identification of an esthetical value, because nowadays they are more and more intended as a resource for the promotion of the creative and innovation process.

Except for their undoubtable cultural value, design archives can be considered an activator for innovation and knowledge exchange. One of the first and most interesting research (Prin, $2008^{3}$ ) based on the idea of the crucial role of design archives is Design and memory of the ephemeral (Lupo \& Trocchianesi, 2013), devoted to the development of a digital archive of exhibitions and their display.

Design archives testify a process, and for this reason they are much more than a mere repository of graphic materials; in many cases, in their integrity, documenting work and personal relations, and documenting the research process through the collecting of samples, models, materials, etc., they hold such a deep and stratified level of knowledge that they can be considered an intangible heritage. That's why they need to be treated, managed, implemented and reused, they can be transformed into innovation spaces, where creativity processes based on knowledge re-use (Sedita, 2012) may act.

From a methodological point of view, the project conducted on the re-activation of the intangible heritage of the network of Milanese artisans is a useful example (Lupo \& Trocchianesi, 2013), as the experience of Harvard metaLAB with its four trajectories of digital humanities research:

storied collections (innovative things we can do with and across collections whether as data aggregates or as curated assemblages of individual records); the social lives of things (multimedia approaches [...]); new learning containers [...], and ubiquitous curation (networks and natures, the world as open-air classroom and laboratory) (Schnapp, 2014, p.7).

Even if these examples of design knowledge pertain to different subject matters and chronologies, they represent methodological models with which we can compare any experiment on design archives: this is a context, in Italy, defined by many different realities, from the personal archives, to the more complex entities held by private or public institutions. We can refer to experiences as the digitization project of the Archivio Magistretti, or the public engagement program developed by Fondazione Franco Albini, or Fondazione Achille Castiglioni in Milan.

Since 2015 the Communication Study Center and Archive of Università di Parma (CSAC) too started a new phase of its activities, just to update its mission. CSAC is an archive that contains original materials illustrating visual communication, artistic and design research, from industrial design, advertising and architecture in Italy starting from the first decades of the 20th century.

The collection began as the result of a program of art exhibitions since 1968, immediately followed by an important nucleus of exhibitions and research devoted to media and photography. The second phase coincided with the creation of the Design department, at the beginnings of 1970s.
3

PRIN 2008. Design for cultural heritage among history, memory and knowledge. Intangible, Virtual, Interactive as a design "matter" in the time of crisis. National coordinator: Politecnico di Milano, resp. F. Irace. 
The inclusion of design disciplines undoubtedly generated the need for new acquisitions policies, to the rules of the archiving of materials, the most important one related to the conception of archive as an anthropological tool of investigation of the contemporary culture.

Today the collections are organized in five sections: Visual Arts, Media, Design, Photography, Theatre and Cinema.

As a result of an evaluation process between 2014 and 2015 a new program has been presented, founded on the transformation of the prevailing research and collecting dimension of the archive into a new interactive dimension. The renovated connections between archive and exposition were intended as a tool to interpret the contemporaneity, reactivating the 20th century heritage, valorizing the connections that the archive allows to emerge.

Since Ettore Sottsass. Oltre il design exhibition (2017) the focus has been on the specificity of the design funds. The cataloguing and the curation proceeded hand to hand with a constant exchange between the study and the analysis of the typology and materiality of the documentation. The exhibition too has been designed focusing on the representation of the Sottsass design methodology and on his idea of design: a creative process applied without any distinction between architecture, industrial design, graphic design, visual arts and so on. The main question on which the design of the display - created by Studio Terragni Architetti and xycomm in an open and on-going debate with the curators has been based was: how can we put the archive at the center, how can we treat each document just to emphasize the stratification of information and its role in-between the creative or design process? So, as always happens, the layout has been a further interpretation on the work of the designer, and the archive has become the generator of experimentation by creatives.

This has been the starting point of a series of actions with which the re-activation of the archive has been the core. Artists in residence have been committed since 2017 to offer their own interpretation of such a complex collection (as the metaLAB Storied collections). The results have been different, even in respect to the design funds. Luca Vitone selection of 'objects' put aside other artworks for his installation // Canone has been based mainly on personal memories, meanwhile Eva Marisaldi in Secondi Tempi exhibition suggested correspondences between images selected from his "personal archive of formation" and projects stored in the CSAC archive. If Vitone acted as a curator underlaying the emotional character of objects, Marisaldi defined a new itinerary in the archive suggesting connections between practices of making objects and the methodology of design or different culture and symbolic systems. The way with which the artists investigate the archive, and observe every item connected to the history of a project stored in the archive should be embodied in the canonical archival practice, from the description policies to the design of narratives through which show unexpected connections. The assumption of regards autres emphasizes once more the relational dimension of the archive. 
The Design! Oggetti processi esperienze exhibition (2020-21), that should have coincided for a short period with Eva Marisaldi Secondi tempi, represents a further occasion to reflect on the representation of the design process, as analyzed in the second section of this paper.

Curatorial idea, in that case, wasn't limited to the selection of projects and to the narratives through items just to show different design culture starting from Castiglioni, Bellini, Menghi, Rosselli, Cini Boeri, Sambonet, Munari, Mari, Mendini, Archizoom and Sottsass jr.

The exhibition, indeed, is the result of different interpretations of the archive: the Francesca Molteni video Archivio Vivo, an additional interpretation for the exhibition, to the commission of new artworks realized by Sissi for the exhibition section devoted to body and fashion design.

Sissi, a Bolognese artist who, since the very beginning, reflected on the bodily dimension through performance, drawings, sculptures and dressmaking, started her work researching in the archive towards the fashion funds of Brunetta, Krizia and Cinzia Ruggeri. Looking at the work of these protagonists of the Italian fashion system, Sissi created three sculpture-dresses realized by three firms. But the challenge has been the working method based on a continuous and synergic collaboration between artist and workers with an exchange of knowledge and skill that started since the first phase of the archival research.

\section{Exhibitions as a Narrative Display of Archives}

In recent years we have been witnessing several exhibitions focused on design which are expressions of a huge patrimony organized in structured archives. In these cases, design exhibitions are an 'active' representation of design archives. In particular, we focus on three design exhibitions that are taking place right now (2020-2021): Design! Oggetti, processi, esperienze (CSAC, Parma); Enzo Mari curated by Hans Ulrich Obrist with Francesca Giacomelli (Triennale di Milano); Fornasetti. Theatrum Mundi (Complesso Monumentale della Pilotta, Parma). In all of these, we can find different kinds of narratives: methodological design processes, authorial products and artistic influences. In the following text we will analyse the exhibitions taking into account different aspects: the explicit or implicit 'archive model', the relationship between placed objects and spaces, the artistic approach in the creative and methodological processes.

Design! Oggetti, processi, esperienze

Taking Out: The Archive Moves to the Exhibit Space

Design! Oggetti, processi, esperienze (curated by Francesca Zanella) - already mentioned in the previous paragraph - is focused on the Italian design proposing crossing readings and different interpretative levels starting from the CSAC archive. Herein, the role of the archive is underlined not only as a place of preservation and valorisation of the design history, but also as an activator of stories through a rereading of the memory. 
The main section of the exhibition - which takes place in the amazing space of Abbazia di Valserena - is articulated into two areas aimed at underlining two different narrative dimensions: the design process and the tale of the objects.

The rich and articulated topic of the collection is verified through curatorial and display systems based on monographic focuses underlined by long hang graphic banners which introduce the lateral spaces (obtained from the side aisles). These sorts of 'open rooms' host white panels on which drawings, sketches, pictures and diagrams of processes are shown.

In the transept area the display system which shows the museum of objects, intentionally refuses the traditional modernist layout based on the artwork on a white base in favour of a metallic wireframe system (at different heights) like a 'variable horizon' archipelago made of monographic and thematic isles.

The majestic central nave is interrupted from metallic archive dressers here used as a display system with which the visitor can interact discovering additional documents (drawings, sketches, notes...) aimed at documenting the creative and design process. This is a clear way to declare the identity of the archive and its exhibit function.
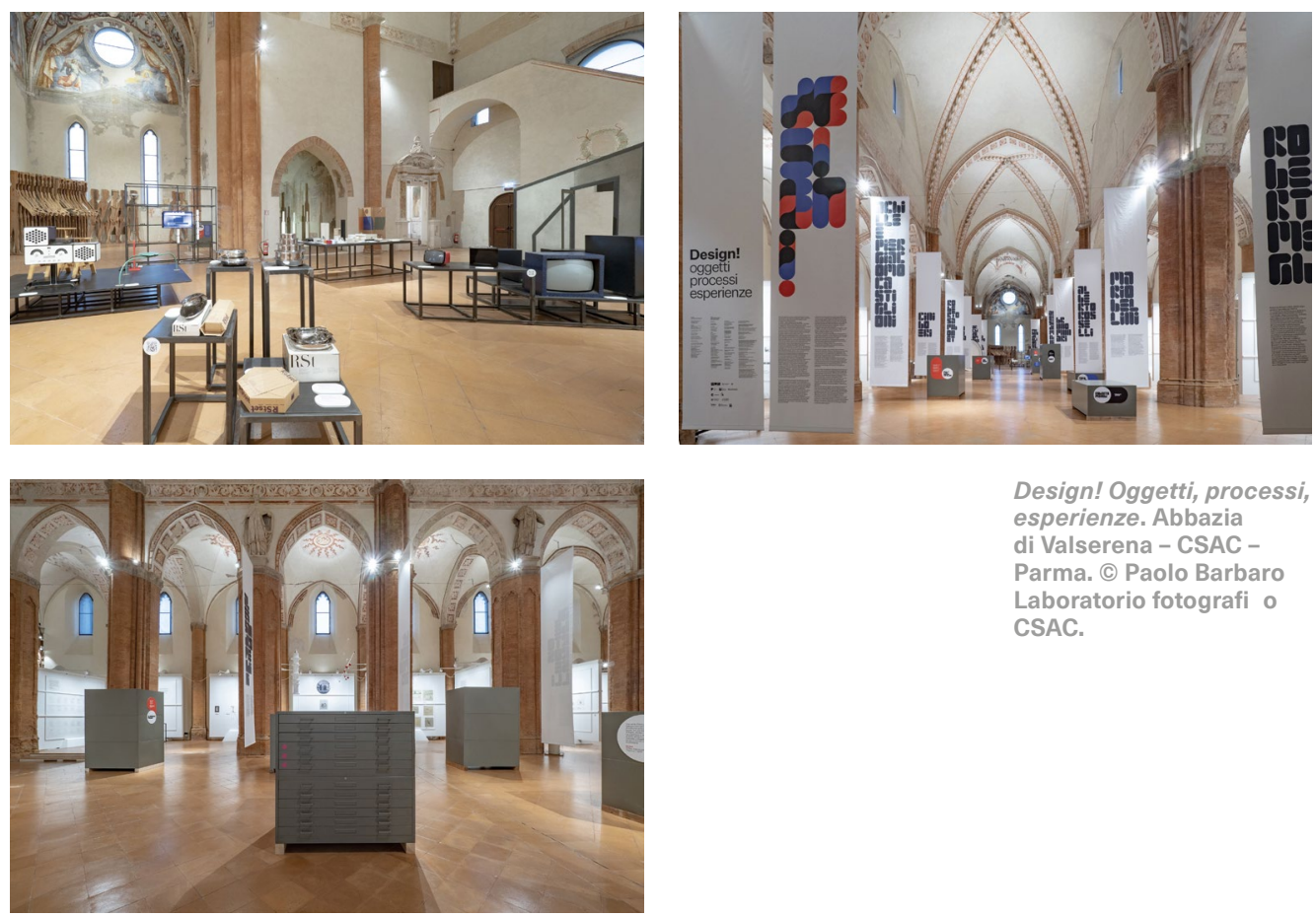

Design! Oggetti, processi, esperienze. Abbazia di Valserena - CSAC Parma. (C) Paolo Barbaro Laboratorio fotografi o CSAC. 


\section{Enzo Mari curated by Hans Ulrich Obrist} with Francesca Giacomelli

Disclosing: The Exhibition Is Expression of the Archive

Before dying, Mari provocatively declared his resolute will to give the whole collection of his works to the city of Milan ${ }^{4}$ providing that nobody has access to it for the next forty years; because just in forty years the new generation can understand and interpret its meaning consciously. At the basis of this statement there is the idea of the 'time settling'. According to his point of view, the legacy of his work is a collection of 'archetypal tools of knowledge': "Everything was obsessively recorded in the programs of the eternity of research, in the methodology of the memory according to Warburg's atlas model" (Giacomelli, 2020, p.76). Mari conceived the research both as verification and as design. He shaped a method as a will to communicate. His purpose was the creation of models for a renovated society where the design is a real design just if it is able to communicate knowledge.

This exhibition (located at the Triennale di Milano) is the Manifesto of his approach; is a journey through his ideas and experimentations ${ }^{5}$. It tells sixty years of design activity: from art to design, from architecture to philosophy, from teaching to graphic design.

The sustainability - in a wide meaning - comprehensive of production processes, materials employed, the research about the 'good shape' and accessible objects is the crucial core of his work and well represented in this exhibition according to his definition of the 'democratization of objects'.

The concept of the exhibition is a sort of 'spread' archive unrolled in a chronological way along the whole space where easel tables, basic theatrical wings and wooden supports are the main artifacts used for the exhibition. Visitors get lost in a design landscape made of objects, artistic experimentations, drawings, pieces of furniture where the product is the expression of the process.

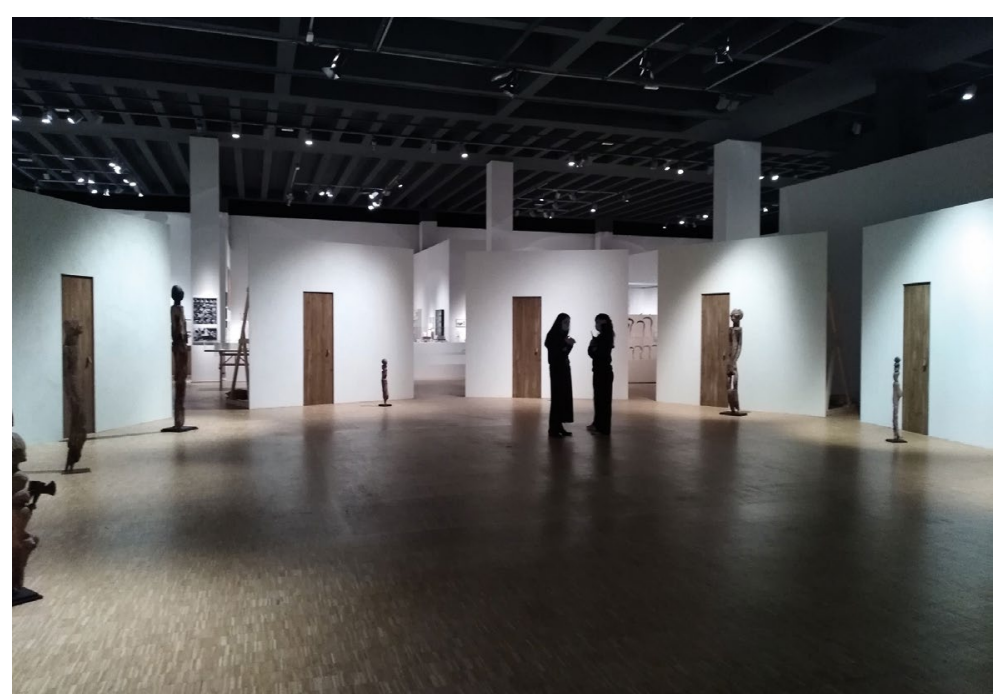

4

Mari's archive will be divided between two institutions. Enzo Mari donated to the CSAC archive 3 works of art in 1977, then in 1978 his archive was constituted by dravings, then a new donation in 1988. Actually the fund is constituted by more than 8400 items documenting his work from 1956 to 1981. The remaining part will be placed at CASVA (Centro di Alti Studi sulle Arti Visive) created by the municipality of Milan in 1999. Today CASVA guards twenty-two professional archives related to architectural, design and graphic fields

\section{5}

The historical section is developed starting from the last Mari's exhibition: Enzo Mari. L'arte del design, happened in 2008 at the GAM, Galleria Civica d'Arte Moderna e Contemporanea in Turin of which Mari signed the curatorship, the display system and the catalogue.

Enzo Mari curated by Hans UIrich Obrist with Francesca Giacomelli. Triennale di Milano. (C) Ra aella Trocchianesi. 

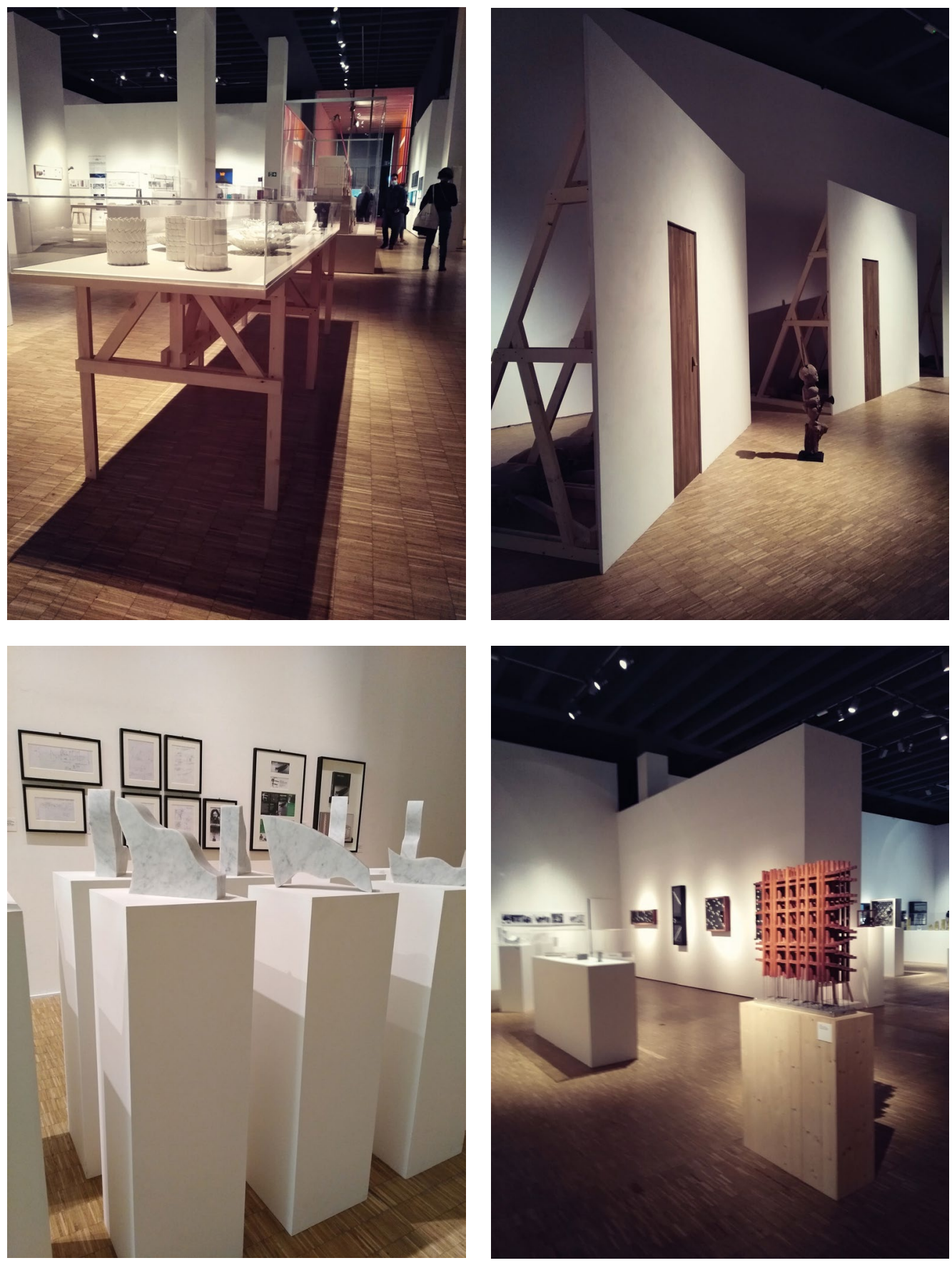

Enzo Mari curated by Hans Ulrich Obrist with Francesca Giacomelli. Triennale di Milano. (C) $\mathrm{Ra}$ aella Trocchianesi. 
Fornasetti's atelier and house is a 'space-manifesto' and at the same time an anthological exhibition, a 'total space' where subjects, stylistic features, chromatic and constituent codes cover - in a scenographic way - the whole surfaces of the space. It is an 'obsessive' collection of objects conceived like devices able to modify the spatial perception (Fornasetti, 2013).

Piero Fornasetti used to organize the pieces of his collages in a 'special' archive in a specific room of his house; a sort of archive dresser full of folders divided in alphabetic order. Each folder collects several illustrations, magazines cuttings, drawings, pieces of inspirations and graphic creations useful for his imaginary compositions. He transformed his house-atelier into a creative repository.

Piero Fornasetti is a multifaceted personality: artist, printer, bibliophile, decorator, gallery owner and collector. Prolific 'imagineer', he created his personal imaginative universe made of visions, bi-dimensional narratives and visual metaphors (this legacy is collected, transmitted and managed by his son Barnaba, artist himself and director of the atelier).

The exhibition Fornasetti Theatrum Mundi (curated by Barnaba Fornasetti, Valeria Manzi and Simone Verde) expresses very well the spirit of this approach. The collection (books, objects, pieces of furniture and so on) is integrated in the place; the objects inhabit the library room, the theater, the rooms of the museum. Each piece dialogues with Palazzo della Pilotta and other pieces of the permanent collection. Its positioning is justified by the relationship with the identity of the place and with a system of visual and symbolic references. In this way we are immerged in a sort of 'world theater': a complex net of iconographical cross references and cultural suggestions, a Theatrum in the 16th century meaning which declares - in a contemporary way - the encyclopaedia of knowledge (longed for by classicism) in the unlimited variety of the world.

The exhibit path is organized in nine sections linked to the main Fornasetti topics: the ruins, the architecture, the music, the variations on the theme, the drawing, the graphic design, the art of collecting, the daily object, and the illusionistic and dreamlike dimension.

The path starts in the Palatina Library Petitot Gallery with several showcases with objects and documents related to the world of books as well as with some pieces are spread around the place: a folding screen decorated coherently with this topic, some books which stick out from the wall supported by Fornasetti's bookends (visitors notice them just if they pay attention to details and hidden signals). The second scenario is the 17th century wooden Farnese Theater: the architectonic idea of Theatrum Mundi conceived by Giulio Camillo philosopher who located figures and symbols organized in a specific order in Vitruvio's theater. This model was the expression of a sort of artificial mind able to comprehend, rebuild and interpret the world. This idea is very close to 
Fornasetti's approach. In this surprising place innumerable plates of Lina Cavalieri series inhabit the terraces as an attending audience, while in the space below some pieces of furniture, decorated with theatrical motifs, play different roles in a continuous reference between actual place and the represented one. Finally, in the rooms of the art gallery we can find other objects which ironically dialogue with the paintings and artworks: small ceramic cats on antique low stools and a dog at the foot of Maria Luigia's sculpture.

The concept of the exhibition is a sort of "stratification" of subjects and 'invasion' of external presences which find their 'natural' positioning in this historical place. The multiplication of this multilayered effect is amplified by writings and quotations by several authors in order to offer further suggestions and keys of interpretation.
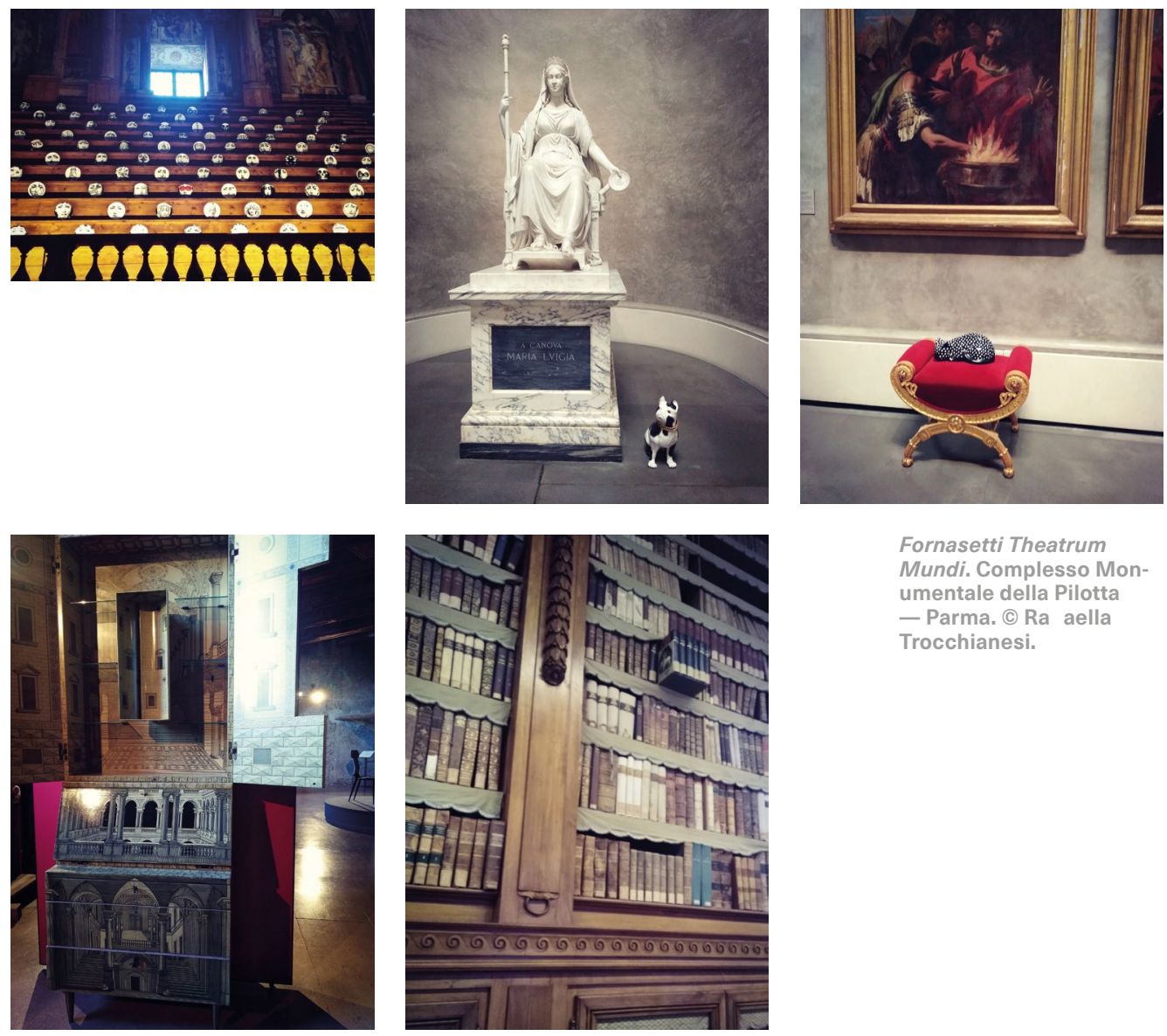

Fornasetti Theatrum Mundi. Complesso Monumentale della Pilotta - Parma. C Ra aella Trocchianesi. 


\section{Conclusions}

In conclusion we can interpret the cases mentioned before using some paradigms recognizable in a bipolar scheme Fig.1 where in the vertical axis we put two opposite models of archive (open archive and hidden archive) and in the horizontal one, two opposite models of relationship between object and exhibition (in place and out of place).

Herein, the paradigm of the exhibition Design! Oggetti, processi, esperienze is taking out because CSAC archive is not only an archive able to collect and preserve materials but it is conceived as an 'open space' which organizes debates, conferences, exhibitions and cultural events. In this case the exhibition takes place in the headquarters of the archive; in terms of display system, this aspect is underlined by the archive dressers which are placed in a way to be consulted and used freely by visitors.

Mari's exhibition could be located between hidden archive and out of place because is an occasion to show a representative collection of the designer's production in an 'external' place (Triennale di Milano). The key paradigm is unveiling according to Mari's idea (we are not sure it will be observed) to close off the archive for forty years.

In the same quarter we can find Fornasetti's exhibition because his archive is accessible just if we visit the house-atelier and because the spirit of this place is moved to another location (Palazzo della Pilotta). Staging is the paradigm chosen because represents a scenographic way to relocate Fornasetti's works in a sort of refined and ironic 'roleplaying' between the objects of the collection and the permanent artworks present in the museum.

The final consideration is about the role of archives and their mission to be creative industries as:

- activators of new ways to enhance the cultural heritage and — in particular in this case - the design culture (all these exhibitions are representative of a specific way to conceive design approaches);

triggers of debates and topics (in these cases processes and products, experimentations and hybridization between art and design, between decorative approach and seriality); scenes of narratives through the 'tool' of the exhibitions and cultural paths (in these cases the three different paradigms represent three ways to interpret the relationship among institutions).
Ra aella Trocchianesi Architect and Associate Professor at Department of Design, Politecnico di Milano. Director of the specialization Master IDEA_Exhibition Design, she mainly deals with Design for Cultural Heritage in terms of museography and exhibition design, communication and enhancement of local areas, new models and narratives of cultural experiences, the relationship among design, humanities and arts.

\section{Francesca Zanella}

Associate Professor at Department of Engineering, Università di Modena e Reggio Emilia. Contemporary Art Historian, her main research fields are the History of Exhibitions, of Architecture and Design. Curator of exhibitions, she is member of the Scientific Committee of CSAC (Università di Parma) and MoRE, a digital museum of unrealized projects. 


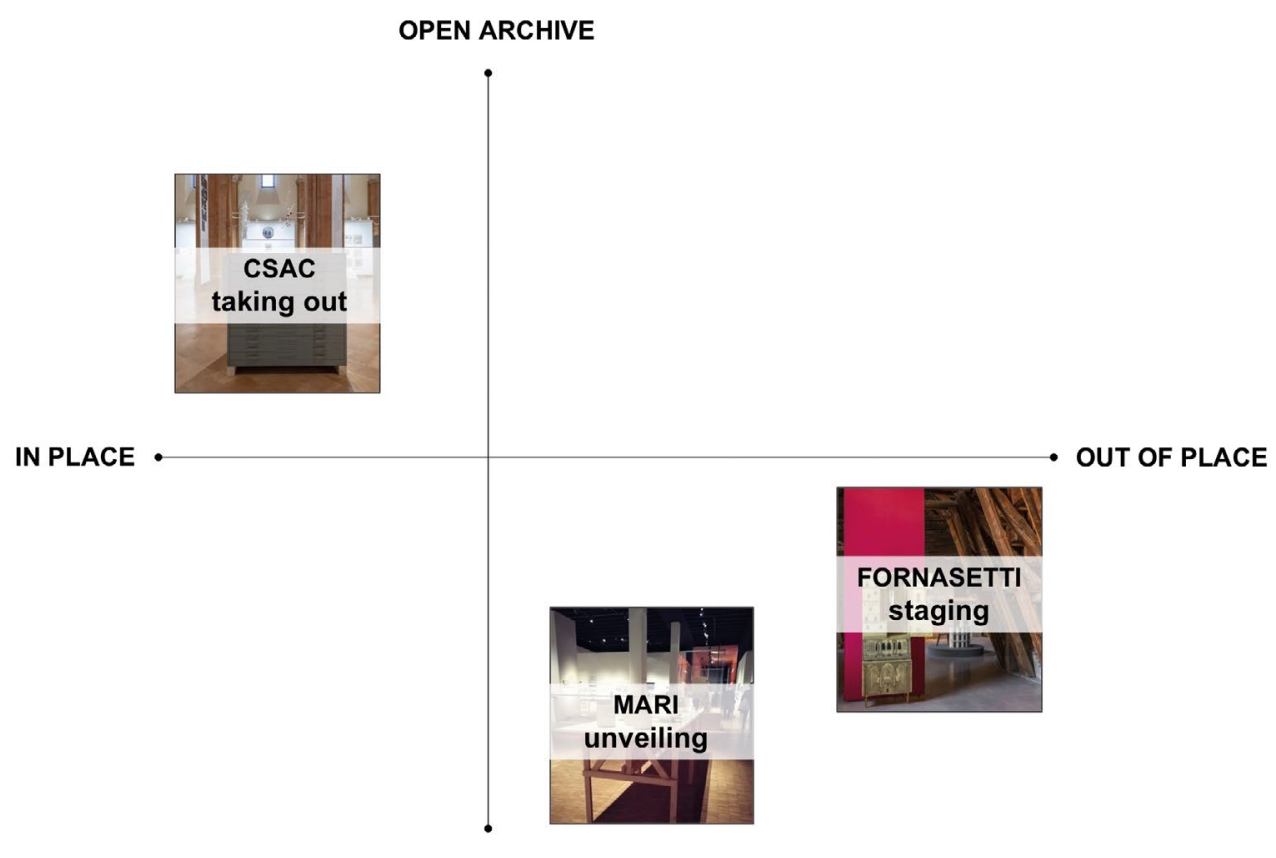

HIDDEN ARCHIVE

\section{References}

Baldacci, C. (2016). Archivi impossibili: un'ossessione dell'arte contemporanea. Johan \& Levi.

Decolonising (2016). Decolonising Archives, L'Internationale online. https://www. internationaleonline.org

Fornasetti, B. (Ed.). (2013). Piero Fornasetti. Cento anni di follia pratica (texts by G. Quadrio Curzio). Corraini Edizioni.

Foster, H. (2004). An Archival Impulse. October, 110, Autumn, 3-22.

Foucault, M. (1969). L'archéologie du savoir. Gallimard.

Derrida, J. (1995). Mal d'archive. Une impression freudienne. Galilée.
Giacomelli, F. (2020). Militanza poetica del costruttore di grammatiche e di rivoluzioni programmate. In H. U. Obrist, F. Giacomelli (Eds.) Enzo Mari curated by Hans Ulrich Obrist with Francesca Giacomelli. Catalogue of the exhibition, October 17, 2020-April 18, 2021. Triennale di Milano. Electa.

Lupo, E. (Ed.). (2013). Autentico contemporaneo. Design e attivazione dei saperi tipici e maestri artigiani milanesi. Maggioli editore.

Lupo, E., \& Trocchianesi, R. (Eds.). (2013). Design and memory of the Ephemeral. Mondadori Electa.

Fig. 1

Exhibition paradigms framed according to the variables of places and models of archive by Ra aella Trocchianesi.

Lupo, E. (2013). Spazializzare la conoscenza attraverso relazioni: dall'archivio al repertorio come "cultural agency". In E. Lupo \& R. Trocchianesi (Eds.), Design\&culturalheritage. Progetto e memoria del temporaneo. Electa, 135140.

Noordegraaf, J. (2011). Remembering the Past in the Dynarchive: The State of Knowledge in - Digital Archives. Paper for the conference Media in Transition 7, Unstable Platforms: The Promise and Peril of Transition. MIT, May 13-15, 2011. http://web.mit.edu/ comm-forum/mit7/papers/ Noordegraaf.pdf
Schnapp, J. (2014). Knowledge Design. Incubating new knowledge forms / genres / spaces in the laboratory of the digital humanities. Herrenhausen Lectures. VolkswagenStiftung, Hannover.

Sedita, S.R. (2012). Leveraging the intangible cultural heritage: novelty and innovation through exaptation. City, culture and society, 3 , 251-259.

Zanella, F. (2019). Tra opera e documento. Percorsi dal museo all'archivio e dall'archivio al museo. Pianob (Sulle tracce del museo), 4, 1, 124-149. 